Review

\title{
Extra Corporeal Life Support in Traumatic Brain Injury Patients
}

\author{
Berta Monleón López ${ }^{1}$, Valentina Della Torre ${ }^{2,{ }^{*}}$, Federico Bilotta ${ }^{3}$, Rafael Badenes ${ }^{1}$
}

1. Department of Anaesthesiology and Surgical Trauma Intensive Care, Hospital Clinic Universitari de Valencia, University of Valencia, Valencia, Spain; E-Mails: berta.monleonlopez@gmail.com; rafaelbadenes@gmail.com

2. Department of Critical Care, Imperial College Healthcare NHS Trust, St Mary's Hospital, London, UK; E-Mail: valentdt@gmail.com

3. Department of Anaesthesia and Intensive Care, University La Sapienza, Rome, Italy; E-Mail: bilotta@tiscali.it

* Correspondence: Valentina Della Torre; E-Mail: valentdt@gmail.com

Academic Editors: Lynne Ann Barker and Leanne Greene

Special Issue: New Developments in Brain Injury

\section{OBM Neurobiology}

2019 , volume 3 , issue 3

doi:10.21926/obm.neurobiol.1903037
Received: June 11, 2019

Accepted: August 19, 2019

Published: August 22, 2019

\begin{abstract}
Purpose of review: The purpose of this review is to describe recent evidence regarding the use of Extracorporeal Membrane Oxygenation (ECMO) as rescue therapy for refractory cardiac or respiratory failure in patients with traumatic brain injury (TBI) when conventional treatments have failed. The characteristics of these patients, including the risk of bleeding and developing malignant intracranial hypertension, are generally considered as relative contraindications to ECMO treatment; however, recent evidence suggests that the use of ECMO should be considered even in this cohort.

Recent findings: Recent findings suggest that venous-venous ( $V-V)$ ECMO can be feasible in the treatment of severe acute respiratory distress syndrome (ARDS) TBI-related. Venousarterial (V-A) ECMO has emerged as a salvage intervention in TBI patients complicated with cardiogenic shock and after cardiac arrest. Improvement of ECMO techniques, including the introduction of centrifugal pumps and heparin-coated circuits, are progressively reducing
\end{abstract}

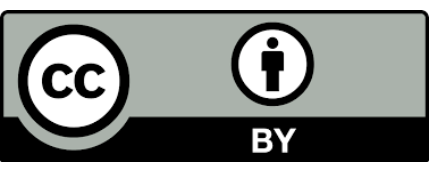

(C) 2019 by the author. This is an open access article distributed under the conditions of the Creative Commons by Attribution License, which permits unrestricted use, distribution, and reproduction in any medium or format, provided the original work is correctly cited. 
the amount of heparin required. Moreover, the application of low dose heparin or heparinfree protocols anticoagulation in ECMO has shown good outcome and minimal bleeding and thrombotic complications.

Summary: ECMO can be considered as a safe and feasible rescue therapy even in TBI patients. However, there is a lack of evidence. Further studies are warranted, focusing on brain trauma patients undergoing ECMO to better clarify the effect on survival, the type and dose of anticoagulation, and the utility of dedicated multidisciplinary trauma-ECMO units.

\section{Keywords}

Acute respiratory distress syndrome; traumatic brain injury; extra corporeal membrane oxygenation; anticoagulation; heparin

\section{Introduction}

Traumatic brain injury (TBI) can be defined as an alteration of brain function or evidence of brain pathology due to an external force [1]. More than 50 million people worldwide have a TBI yearly. TBI has been shown to shorten life expectancy by six years [2]. It is the leading cause of mortality within young adults. Statistics show that in high-income countries (HIC) the number of TBIs in the elderly is increasing due to falls, while in middle- low-income countries (MLIC) the incidence of TBI is increasing due to an increase in traffic road accidents. Epidemiology of TBI is a difficult issue due to significant differences in data collection within different countries [3]. Different countries have reported different mortality rates. The Eurostat Data from 25 countries calculated a pooled age-adjusted mortality rate of 11.7 per 100000 people in 2012 [3]. Mortality data from severe TBI, defined as Glasgow Coma Scale (GCS) $<9$, range from 30 to $40 \%$ [1] (Table 1).

Table 1 Grading TBI with GCS and loss of consciousness (LOC).

\begin{tabular}{|l|l|l|}
\hline & GCS & LOC \\
\hline Mild & $13-15$ & $0-30 \mathrm{~min}$ \\
\hline Moderate & $9-13$ & $30 \mathrm{~min}-24 \mathrm{hrs}$ \\
\hline Severe & $3-8$ & $>24 \mathrm{hrs}$ \\
\hline
\end{tabular}

Surviving patients of TBI's suffer from physical, psychiatric, emotional and cognitive disabilities. Disrupting lives of patients and families generates enormous costs to society. It is important to design a tool that characterises the under-recognised risk of long-term disabling sequelae in patients with relatively mild injuries [4]. The individual impact of mild TBI (GCS between 9 and 12) is less, but it makes a larger contribution to the global burden of disability. The public health consequences of TBI are often referred to as 'years of life lost' (YLL), which give an estimate of the number of years a person would have lived if he or she had not died prematurely [1]. Most multicentre clinical trials of medical and surgical interventions for TBI treatment have failed to show benefits on neurological outcomes. Nowadays, we mostly use strategies based on guidelines 
that do not promote an individualised treatment. It is very difficult to apply an individualised medicine in TBI, due to the great diversity of the disease [5]. Among brain injury, it is crucial to differentiate the primary damage (that inflicted at the time of the injury) from the secondary damage (which develops over hours, days, weeks and even months) [4,5]. The secondary damage corresponds to the host response to primary damage. In terms of a modern and holistic approach, TBI needs to be considered as a progressive disease with long-term consequences. For the management of TBI patients, a multidisciplinary approach is necessary. TBI is also associated to chronic sequelae, such as epilepsy, stroke, and late-life neurodegenerative diseases.

\section{Indications}

TBI patients can develop respiratory and cardiac complications leading to cardiopulmonary failure, therefore Extra Corporeal Support, in some cases, has to be considered. ECMO is an advanced technique that provides temporary respiratory (veno-venous, V-V configuration) or cardiac (veno-arterial, V-A configuration) support in patients with cardiopulmonary failure. The incidence of ARDS in TBI patients is not well reported. Aisiku et al. reported an incidence of 20$25 \%$ in their cohort of patients [6]. According to the Berlin Definition, ARDS is defined as an acute hypoxemic respiratory distress syndrome, not fully explained by cardiac failure, occurring within one week of a known clinical insult, or new or worsening respiratory symptoms, with bilateral opacities on chest X-ray [7] (Table 2).

Table 2 Berlin definition of ARDS [8].

\begin{tabular}{|l|l|}
\hline Timing & $\begin{array}{l}\text { Within } 1 \text { week of a known clinical insult or new or worsening } \\
\text { respiratory symptoms }\end{array}$ \\
\hline Chest Imaging & $\begin{array}{l}\text { Bilateral opacities }- \text { not fully explained by effusions, lobar/lung } \\
\text { collapse, or nodules }\end{array}$ \\
\hline Origin of Edema & $\begin{array}{l}\text { Respiratory failure not fully explained by cardiac failure or fluid } \\
\text { overload. } \\
\text { Need objective assessment [e.g., echocardiography) to exclude } \\
\text { hydrostatic oedema if no risk factor present }\end{array}$ \\
\hline Oxygenation & $200 \mathrm{mmHg}<\mathrm{PaO}_{2} / \mathrm{FIO}_{2} \leq 300 \mathrm{mmHg}$ with PEEP or $\mathrm{CPAP}_{2} \geq 5 \mathrm{cmH}_{2} \mathrm{O}^{\mathrm{c}}$ \\
\hline Mild & $100 \mathrm{mmHg}_{2}<\mathrm{PaO}_{2} / \mathrm{FlO}_{2} \leq 200 \mathrm{mmHg}$ with PEEP $\geq 5 \mathrm{cmH}_{2} \mathrm{O}$ \\
\hline Moderate & $\mathrm{PaO}_{2} / \mathrm{FIO}_{2} \leq 100 \mathrm{mmHg}$ with PEEP $\geq 5 \mathrm{cmH}_{2} \mathrm{O}$ \\
\hline Severe &
\end{tabular}

Trauma patients with severe injuries are at risk of developing ARDS requiring ECMO support from both direct and indirect causes, including lung contusions, aspiration pneumonia, massive blood transfusion and fat embolism syndrome (Figure 1). Moreover, ECMO allows temperature and acid-base balance control, avoiding the lethal triad of metabolic acidosis, coagulopathy, and hypothermia [9]. 


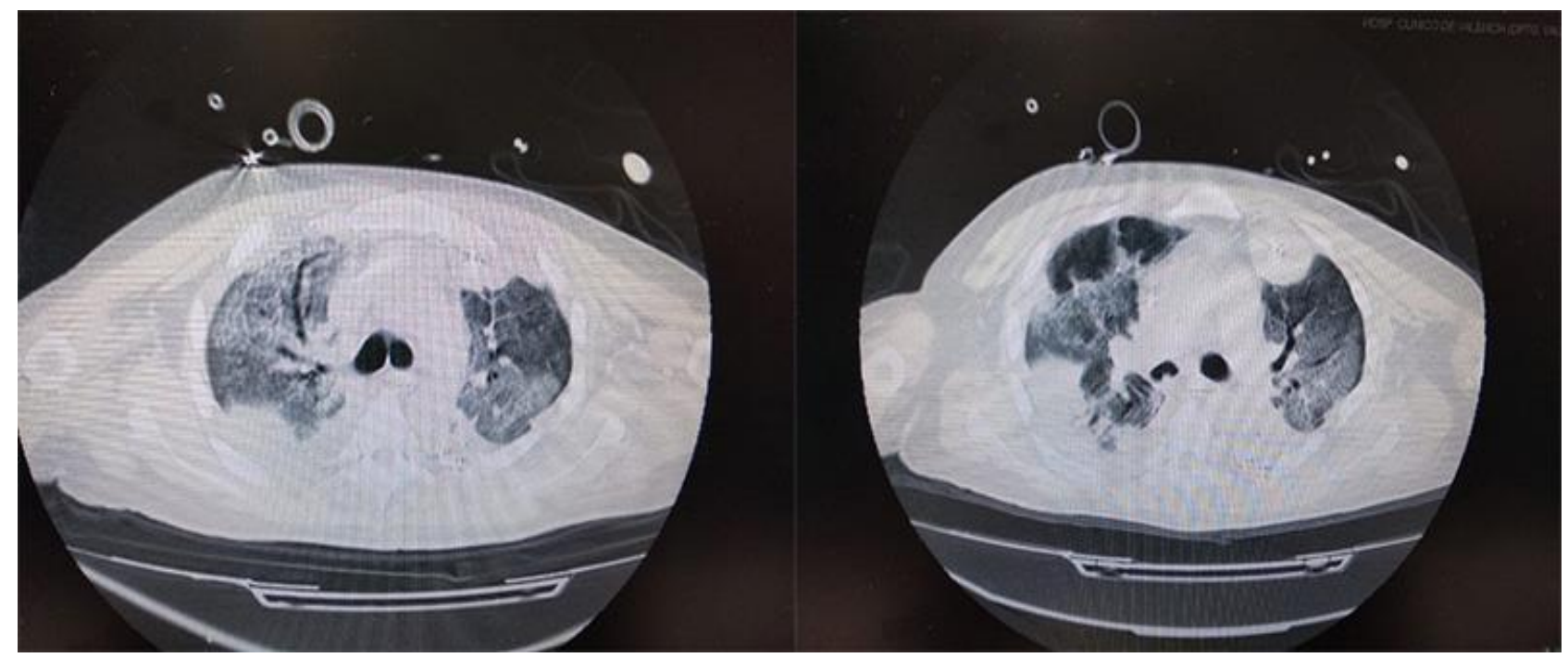

Figure 1 Chest CT scans of a patient with severe ARDS.

Various clinical trials have been designed to evaluate the effect of ECMO on trauma patients, resulting in survival rates varying from $30 \%$ to $75 \%$ [10-13]. These differences in results are due to non-protocolised treatment, different ECMO starting points, variable anticoagulation strategies and patients' characteristics. There are no guidelines available, therefore, ECMO therapy is usually considered as the rescue therapy when ventilatory strategies fail. In the EOLIA study [14], nontrauma patients, with severe ARDS who reached one of the-set criteria, were eligible to receive $\mathrm{V}$ $\checkmark$ ECMO or conventional treatment. 60-day mortality was not significantly different between groups and neither were complications rates. Patients refractory to ventilatory therapies, recruitment manoeuvres or prone position may be eligible to ECMO therapy, although no general consensus has been reached. Special care has to be taken with neuro-patients because all of these strategies can increase the risk of intracranial hypertension $[15,16]$. The whole cerebral haemodynamic system can be affected, decreasing both cerebral perfusion pressure (CPP) and cerebral blood flow (CBF). When recruiting the lungs, increased PEEP decreases return of blood flow from the brain, increasing intracranial pressure (ICP). Mean arterial pressure (MAP) also decreases, thus the increase in ICP and reduction of CPP. Hypoxia produces vasoconstriction, which can increase ischaemic areas, while hypercapnia vasodilates brain vessels, contributing to the increase in ICP (Table 3). The pathophysiology of lung injuries after an acute brain injury is still debated, and several theories have been proposed; recently, the "double hit" model has been described [17]. The sympathetic response to increased ICP also has an important role [18]. After brain injury, an inflammatory response occurs with the release of inflammatory mediators that are transferred to the systemic circulation, when the blood brain barrier is altered. Other organs are affected by these inflammatory cytokines (known as 'first hit') and become more susceptible to further events (known as 'second hit') such as mechanical ventilation, infections or surgical interventions. The catecholamines' response exacerbates this secondary damage [19] (Figures 2 and 3).

In V-V and V-A ECMO, anticoagulation is needed to allow the extra corporeal circuit to run without formation of clots; therefore the main complication is bleeding. Recent or active bleeding is a contraindication to ECMO therapy, thus theoretically excluding almost all TBI patients. However, due to the advances in the centrifuge pumps and the coagulated-coated circuits, the 
need for anticoagulation doses has decreased; in some circumstances, anticoagulation can be avoided altogether, allowing ECMO to run without systemic heparin [20]. This allows physicians to reconsider it as a feasible therapy in the context of TBI.

Table 3 Differences in optimal ventilatory parameters between TBI patients and ARDS patients [21].

\begin{tabular}{|c|c|c|}
\hline Ventilatory & TBI (traumatic brain injury) & $\begin{array}{l}\text { ARDS (acute respiratory distress } \\
\text { syndrome) }\end{array}$ \\
\hline $\mathrm{PaO}_{2}$ & $\begin{array}{l}\text { Normoxia: } \mathrm{PaO}_{2}>60 \mathrm{mmHg} \\
\text { (Brain Trauma Foundation); } \\
\mathrm{PaO}_{2}>97 \mathrm{mmHg} \text { (UK Transfer } \\
\text { Guidelines) }\end{array}$ & $\mathrm{PaO}_{2}$ 55-88 mmHg (ARDS Network) \\
\hline $\mathrm{PaCO}_{2}$ & $\begin{array}{l}\text { Normocapnia } \mathrm{PaCO}_{2} \text { ranges } \\
\text { from } 35-45 \mathrm{mmHg} \text {; prolonged } \\
\text { prophylactic hyperventilation } \\
\text { with } \mathrm{PaCO}_{2}<25 \mathrm{mmHg} \text { is not } \\
\text { recommended. }\end{array}$ & $\begin{array}{l}\mathrm{pH}>7.30 \text {, permissive hypercapnia } \\
\text { accepted }\end{array}$ \\
\hline PEEP & $\begin{array}{l}\text { PEEP < ICE; provide MAP is } \\
\text { maintained }\end{array}$ & Incremental $\mathrm{FiO}_{2} / \mathrm{PEEP}$ combination \\
\hline Plateau Pressure & $<30 \mathrm{~cm} \mathrm{H}_{2} \mathrm{O}$ & $<30 \mathrm{~cm} \mathrm{H}_{2} \mathrm{O}$ \\
\hline Prone Positioning & $\begin{array}{l}\text { Reasonable to attempt when } \\
\text { severe hypoxemia, with strict } \\
\text { neuromonitoring. }\end{array}$ & $\begin{array}{l}\text { Improve } \mathrm{PaO}_{2} / \mathrm{FiO}_{2} \text { ratio; suggestion } \\
\text { to use prone position when } \mathrm{P} / \mathrm{F}< \\
150 \mathrm{mmHg}\end{array}$ \\
\hline $\begin{array}{l}\text { Recruitment } \\
\text { Manoeuvres }\end{array}$ & $\begin{array}{l}\text { Reasonable to attempt when } \\
\text { severe hypoxemia, with strict } \\
\text { neuromonitoring. }\end{array}$ & $\begin{array}{l}\text { Incremental } \\
\text { combination. }\end{array}$ \\
\hline iNO & No evidence of benefit. & $\begin{array}{l}\text { Limited evidence available, rescue } \\
\text { therapy? }\end{array}$ \\
\hline $\begin{array}{l}\mathrm{ECCO}_{2} \mathrm{R} \\
\text { (extracorporeal carbon } \\
\text { dioxide removal) }\end{array}$ & $\begin{array}{l}\text { Rescue therapy; should be } \\
\text { considered } \\
\text { (Limited evidence available) }\end{array}$ & $\begin{array}{l}\text { Rescue therapy; should be } \\
\text { considered individually. (Limited } \\
\text { evidence available) }\end{array}$ \\
\hline ECMO & $\begin{array}{l}\text { Reasonable to attempt in } \\
\text { selected cases; use of heparin } \\
\text { needs further studies. }\end{array}$ & $\begin{array}{l}\text { Improves outcomes in patients } \\
\text { referred to ECMO centres. }\end{array}$ \\
\hline
\end{tabular}




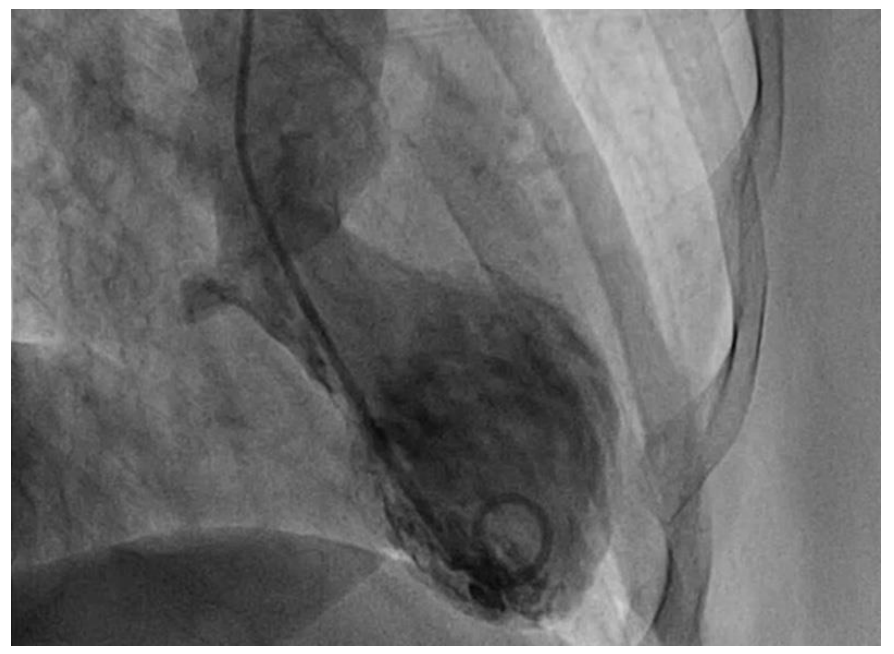

Figure 2 Ventriculography showing morphology of ventricle with Tako Tsubo syndrome.

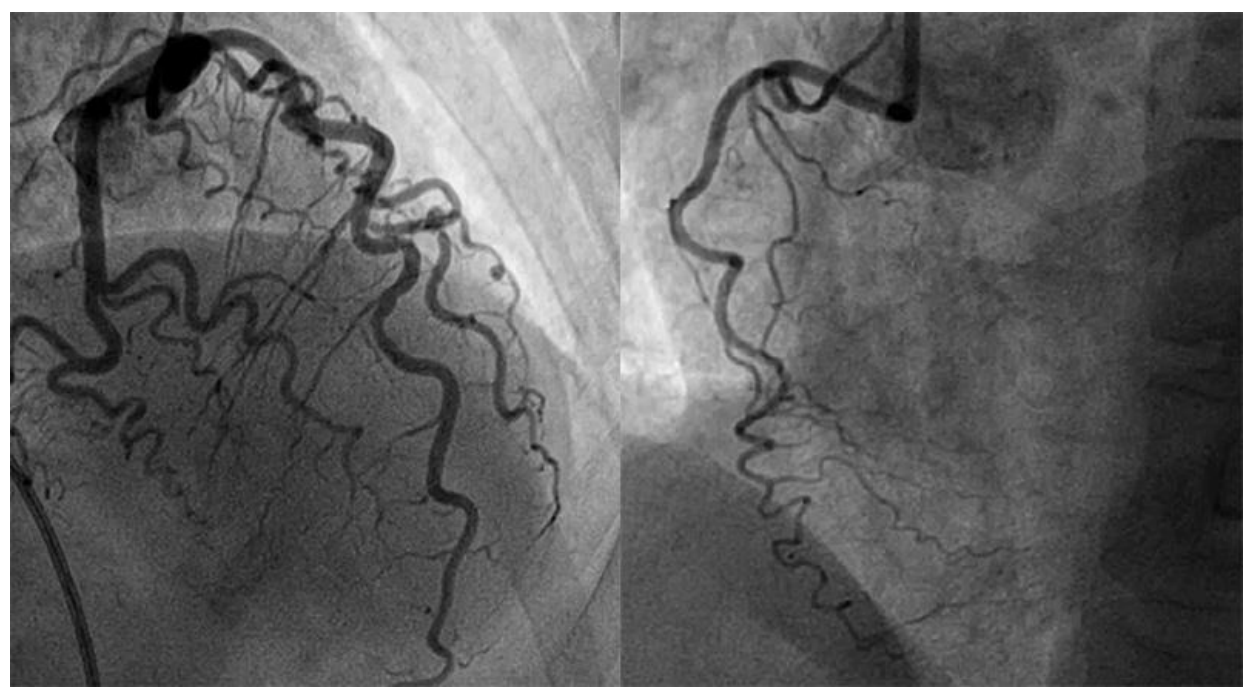

Figure 3 Normal coronaries' arteriography in Tako Tsubo Syndrome.

V-A ECMO could be considered in trauma patients who develop cardiac failure, and in patients with acute cardiac injuries, such as myocarditis and myocardial ischemia; ECMO can be also used as a bridge to recovery. These patients usually have one or more theoretical contraindications for ECMO therapy; however, advances in the extra corporeal technique allow it to be implemented in traumatized patients [22].

\section{Timing of ECMO in TBI Patients}

There is no clear evidence on when to start ECMO, as no clinical trials have been done until now. Muellenbach et al. [23] reported 3 cases of severely traumatized patients with TBI who developed severe ARDS, in whom ECMO therapy was implemented. In the 3 cases, ECMO was started in the first $24 \mathrm{hrs}$ following the trauma event and ECMO was implemented heparin-free. One patient was not anti coagulated until day 5 , second patient until day 2 and third patient until day 3. Then, low dose heparin infusion was started. No bleeding complications due to ECMO were observed. All patients were discharged to neurological rehabilitation units with good recovery outcomes. Biscotti et al. [24] published 2 cases of multi-traumatized patients with an associated 
TBI that needed ECMO therapy. Both patients commenced ECMO at day 4, and heparin infusions were started in both patients. Decannulation of ECMO happened without any bleeding or thromboembolic complications, and both had a complete neurologic recovery. Munoz-Bendi et al. [25] reported 10 patients with TBI who developed ARDS in whom a pump less extracorporeal lung assistant ( $\mathrm{pECLA}$ ) device was used to decrease PaCO2 values. Therapy was started after 24-48 hrs after diagnosis of ARDS and again all of them were anti coagulated with heparin. No bleeding complications were reported. One recent multicentre review showed no significant differences in bleeding or thrombosis complications, exacerbation of primary traumatic injury or worsening of neurological injury between coagulated and non-anti coagulated patients who underwent ECMO therapy, even though the time from injury to ECMO was 6 days [26].

No indications on when to start ECMO are given by the Extracorporeal Life Support Organization (ELSO), although best results are reported when ECMO implemented in the first 24$48 \mathrm{hrs}$. Our review shows that there is still no guidance on the optimum time to start ECMO in either trauma or TBI patients.

\section{Anticoagulation Choiches}

Since extracorporeal life support therapy started, many advances have been made, however, we are still unable to control the interaction between blood and the biomaterials of the circuit. It is known that this leads to an inflammatory and coagulation response, which results in potential bleeding and thrombotic complications [27]. The main objective of anticoagulation in ECMO is to find the balance between antithrombotic therapy, which minimizes clot formation, and endogenous pro-coagulant activity, to avoid bleeding $[28,29]$. Based on the ELSO anticoagulation guidelines [29], baseline laboratory values of coagulation state of the patient should be obtained. These include prothrombin time (PT), international normalized ratio (INR), activated partial thromboplastin time (APTT), Fibrinogen, D-dimer, activated clotting time (ACT), antithrombin activity (AT) and thromboelastography (TEG) or thromboelastometry (ROTEM). The most chosen anticoagulant therapy is un-fractioned heparin (UNFH). As it is well known, the anticoagulant effect of UNFH is mediated by its interaction with two endogenous anticoagulants: antithrombin (AT) and tissue factor pathway inhibitor (TFPI). UNFH inhibits thrombin after it is formed, but it does not prevent thrombin formation, nor does it inhibit thrombin already bound to fibrin [30]. First step of the anticoagulation starts at cannulation time. Here is when a first bolus of heparin (50-100 units per $\mathrm{kg}$ ) is administered. Then, a continuous infusion is maintained. In trauma patients, it might be reasonable to carry out blood analysis just before cannulation to adjust the dose. The ELSO Guidelines [29] recommend initiating the infusion rate at a dose of 7.5-20 units $/ \mathrm{kg} / \mathrm{hr}$, when the measured ACT drops to 300 seconds or below. Therapeutic anticoagulation, classically defined by ACT range of 180-220 seconds, is typically achieved with UNFH infusion rates of 20-50 units $/ \mathrm{kg} /$ hour. New anticoagulants have been tested into practice and they may have a role in some specific group of patients, such as TBI patients [31,32]. Direct thrombin inhibitors are short acting anticoagulants that bind to active sites on thrombin directly and have shown more predictable pharmacokinetics and greater reduction of thrombin generation, as compared to UNFH. The pharmacodyna mics is less affected by external factors, and less bleeding has been seen compared to UNFH. They do not cause immune mediated thrombocytopenia. They are not so widely used because they lack a reverser, but they have relatively short half-lives. Their use in TBI 
patients could be consider, however clinical trials should be done. The three synthetic anticoagulants used have been argatroban, bivalirudin and lepirudin [31-34]. Argatroban has been most often cited new anticoagulants in ECLS applications [31, 35]. Infusions of argatroban are started at $0.5-1 \mathrm{mcg} / \mathrm{kg} / \mathrm{min}$ and adjusted to maintain APTT 1.5-2.5 times baseline values. No available reversers for this drug either. Another alternative is nitric oxide (NO). It is a natural molecule released from the endothelium, which prevents platelet aggregation. In an experimental animal study, the addition of NO to the ECMO circuit improved the platelet activation and consumption process [36]. Both prostacyclin and NO, added to extracorporeal circuits along with UNFH, in an effort to inhibit the interaction between platelets and extracorporeal surfaces, have been shown to reduce platelet activation and consumption [37]; therefore, dosage of UNFH can be decreased.

When monitoring the anticoagulation therapy, different parameters can be used. ELSO Guidelines [29] recommend the use of more than one parameter, but states that using multiple tests would complicate the management. They recommend the use of ACT plus one of the elaborated tests such as Anti-Factor Xa Activity Levels, APTT or TEG and ROTEM. In trauma patients, such as TBI patients, TEG and ROTEM provide information relating to multiple phases of coagulation. Platelet function and fibrinogen are also analysed in these two tests.

The improvement of ECMO techniques, including the introduction of centrifugal pumps and heparin-coated circuits, are progressively reducing the amount of hepa rin required; moreover, the application of heparin-free ECMO showed good outcomes and minimal complications. The need for full, half or no loading dose of heparin should be considered case-by-case [20]. The study by Yen et al. shows no bleeding or clotting complications without systemic UNFH, just heparinbonded circuit [38]. Mullenbach et al. also report a series of heparin-free ECMOs with no major complications [23]. In a case study reported by Friesenecke et al, [39] a severely traumatized patient who developed ARDS was managed with UNFH. Under ECMO therapy, cerebral bleeding was observed and was successfully drained after craniotomy, while maintaining ECMO support. In a study by Biscotti et al [24], two cases of TBI treated with ECMO were reported. First patient was treated with an UNFH infusion and titrated to target aPTT between 40 and $60 \mathrm{~s}$. Full neurological recovery was achieved in this patient. Second patient went also under heparin infusion, with median aPTT of 51s while on ECMO. He was successfully decannulated from ECMO and also had a fully neurological recovery.

In conclusion, un-fractioned heparin is still the most frequent anticoagulant used. However, alternatives are rising, which have to be taken into consideration. Not every patient will need the same anticoagulant dose; risks-benefits should be analysed when choosing and dosing anticoagulants. In TBI patients, probably no heparin infusion and heparin-bonded extracorporeal circuits are the best choices.

\section{Complications of Extra Corporeal Therapy, Bleeding and Anticoagulation in Trauma Patients Undergoing ECMO}

The most common complications associated with ECMO can be divided in those directly related to the ECMO circuit, (oxygenator failure, clots in the circuit and problems related to the cannula and cannula sites) and those not directly related to the ECMO circuit (haemorrhage, infections and haemolysis). Nosocomial infections occur in the $15 \%$ of cases, while haemorrhagic complications 
(excluding intracranial) account for the $14 \%$ of total complications [40]. Ischemia of the lower limb, due to obstruction of the vascular lumen caused by the arterial cannula, can be also a common complication [40]. To minimise the risk of ischemia, a second smaller cannula should be placed distally to perfuse the limb [20]. Bleeding remains the most common complication in these patients. This occurs due to the systemic anticoagulation, as well as the state of thrombocytopenia and thrombocytopathies, result of the extracorporeal circuit.

Mazzeffi et al. [41] observed that contact activation occurs during ECMO, but procoagulant factor levels are generally preserved. Although heparin-neutralized thrombin generation (TG) is delayed, peak TG and endogenous thrombin potential are supranormal in the setting of high FVIII and low AT and protein C levels. Resistance to thrombo modulin is also apparent. These changes demonstrate a possible mechanism for hypercoagulability during adult VA ECMO [41].

Martucci et al investigated the effect of different cannula designs on the amount of blood product transfused in patients on VV ECMO [42]. The group concluded that using a more biocompatible and shorter drainage cannula may represent one of the contributing factors to a reduction in transfusions and costs of VV-ECMO. The same group also found and association between lower ATIII and increased need for transfusions [43]. Higher packed red blood cell transfusions were also associated with mortality during extra corporeal support. Therefore they suggested a personalized transfusion practice in ECMO setting [43].

The Guidelines by the Extracorporeal Life Support Organization (ELSO) state that, when bleeding is present, first step is to optimize anticoagulation status by avoiding 'over-anti coagulated patients (the activated clotting time (ACT) should not be more than 1.5 times the normal value) [44]. Guidelines states to consider platelets transfusion to reach more than $100 \times 10^{9}$ PLT and, if fibrinolysis is suspected, anti fibrinolytics should also be considered. Fresh plasma would be an option when there is a deficit in coagulation factors. If bleeding continues, anticoagulation should be stopped. Most frequent bleeding spot is the cannulation site. Second place where bleeding is common is any recent operations' sites, mainly thoracotomies. In nonacute brain injury patients, bleeding into the head or brain parenchyma is the most serious complication. Cerebral haemorrhage is usually extensive and fatal, and when indicated, it is reasonable to operate the skull to drain blood. In general, a bolus of heparin is administered before insertion of the ECMO cannula, and then heparin infusion is started [45]. Over the last 20 years, there have been multiple technological advances in ECMO, which may allow for its safer use in trauma patients. These advancements include the use of polymethylpentene membrane oxygenators, centrifugal pumps, miniaturization of circuits, and heparin-bonded circuits. Short circuit length and heparin-bonded circuits have proven to decrease the incidence of haemorrhagic complications [46]. Compared with traditional ECMO circuits, heparin-bonded circuits are associated with less blood loss, better platelet function, and decreased leukocyte and complement activation, which result in shorter ventilation time and short hospital stay. Some authors [23] (recently proposed the application of heparin-free ECMO, showing good outcomes and no complications. Chen et al. [47] used VV ECMO without anticoagulation in 7 polytraumatic patients without any haemorrhagic complications. Other authors proposed the use of half dose of heparin, with the use of heparin-bonded circuits, which allow systemic heparin dose to be decreased by half, from $4 \mathrm{mg} / \mathrm{Kg}$ to $1.5 \mathrm{mg} / \mathrm{Kg}$ [48]. Results of a recent multicentre review on trauma patients under ECMO therapy did not support neurological injury as an absolute contraindication to ECMO [26]. The authors did not have significant differences in bleeding between coagulated and non- 
anticoagulated patients, however the median injury-to ECMO time was 6 days, longer than in some other studies [26]. This might be explained because the acute coagulopathy phase is mainly during the first 24 hours from trauma [49, 50]. However, there is lack of consensus among the studies about when to start anticoagulation, or in which situations is better to avoid any anticoagulation, therefore the decision is individualised in each centre $[49,51]$.

ECMO can be associated with neurological complications, such as seizures, ischemic or hemorrhagic stroke, and acute disseminated encephalomyelitis in H1N1-affected patients [52]. Approximately $7 \%$ of adults supported with veno-venous extracorporeal membrane oxygenation had neurologic injury. Intracranial hemorrhage was the most frequent type, and survival for patients with neurologic injury was poor, ranging from brain death to prolonged ICU stay and long term disability [53]. Future investigations should evaluate anticoagulation management as well as brain/extracorporeal membrane oxygenation interaction to reduce these life-threatening events [54]. We therefore advise strict neurological monitoring involving neuro-intensivists, neurologists and neuroradiologists.

\section{Conclusion}

Growing evidence suggests the potential use of ECMO for the treatment of refractory respiratory and cardiac failure in adults, but the clinical benefit in head injury patients is not clear. The selection of patients and the timing for starting extra corporeal support are crucial for success, and before starting ECMO, risks and benefits must be considered on a case-by-case basis. The use of heparin should be carefully considered after a multidisciplinary discussion, involving trauma surgical team, anaesthetists, intensivists and neurosurgeons. Further studies will be warranted to evaluate the role and effect on outcome of ECMO in TBI patients, as well as the need for organization of dedicated trauma-ECMO units.

\section{Author Contributions}

All authors contributed to conceptualizing and designing this review. BML and VDT drafted the manuscript. BML, VDT, FB and RB commented for important intellectual content and made revisions. All authors read and approved the final version of the manuscript. VDT and RB accept full responsibility for the finished manuscript and controlled the decision to publish.

\section{Competing Interests}

The authors have declared that no competing interests exist.

\section{References}

1. Maas AIR, Menon DK, Adelson PD, Andelic N, Bell MJ, Belli A, et al. Traumatic brain injury: Integrated approaches to improve prevention, clinical care, and research. Lancet Neurol. 2017; 16: 987-1048.

2. Majdan M, Plancikova D, Maas A, Polinder S, Feigin V, Theadom A, et al. Years of life lost due to traumatic brain injury in Europe: A cross-sectional analysis of 16 countries. PLoS Med. 2017; 14: e1002331. 
3. Majdan M, Plancikova D, Brazinova A, Rusnak M, Nieboer D, Feigin V, et al. Epidemiology of traumatic brain injuries in Europe: A cross-sectional analysis. Lancet Public Health. 2016; 1: e76-e83.

4. Coronado VG, McGuire LC, Sarmiento K, Bell J, Lionbarger MR, Jones CD, et al. Trends in traumatic brain injury in the US and the public health response: 1995-2009. J Safety Res. 2012; 43: 299-307.

5. Johnson WD, Griswold DP. Traumatic brain injury: A global challenge. Lancet Neurol. 2017; 16: 949-950.

6. Aisiku IP, Yamal JM, Doshi P, Rubin ML, Benoit JS, Hannay J, et al. The incidence of ARDS and associated mortality in severe TBI using the Berlin definition. J Trauma Acute Care Surg. 2016; 80: 308-312.

7. Ranieri VM, Rubenfeld GD, Thompson BT, Ferguson ND, Caldwell E, Fan E, et al. Acute respiratory distress syndrome: The berlin definition. Jama. 2012; 307: 2526-2533.

8. Fanelli V, Vlachou A, Ghannadian S, Simonetti U, Slutsky AS, Zhang H. Acute respiratory distress syndrome: New definition, current and future therapeutic options. J Thorac Dis. 2013; 5: 326.

9. Dreizin D, Menaker J, Scalea TM. Extracorporeal membranous oxygenation (ECMO) in polytrauma: What the radiologist needs to know. Emerg Radiol. 2015; 22: 565-576.

10. Madershahian N, Wittwer T, Strauch J, Franke UF, Wippermann J, Kaluza M, et al. Application of ECMO in multitrauma patients with ARDS as rescue therapy. J Card Surg. 2007; 22: 180-184.

11. Kopp R, Bensberg R, Henzler D, Niewels A, Randerath S, Rossaint R, et al. Hemocompatibility of a miniaturized extracorporeal membrane oxygenation and a pumpless interventional lung assist in experimental lung injury. Artif Organs. 2010; 34: 13-21.

12. Arlt M, Philipp A, Voelkel S, Rupprecht L, Mueller T, Hilker M, et al. Extracorporeal membrane oxygenation in severe trauma patients with bleeding shock. Resuscitation. 2010; 81: 804-809.

13. Cordell-Smith JA, Roberts N, Peek GJ, Firmin RK. Traumatic lung injury treated by extracorporeal membrane oxygenation (ECMO). Injury. 2006; 37: 29-32.

14. Combes A, Hajage D, Capellier G, Demoule A, Lavoué S, Guervilly C, et al. Extracorporeal membrane oxygenation for severe acute respiratory distress syndrome. N Engl J Med. 2018; 378: 1965-1975.

15. Borsellino B, Schultz MJ, Gama de Abreu M, Robba C, Bilotta F. Mechanical ventilation in neurocritical care patients: A systematic literature review. Expert Rev Respir Med. 2016; 10 : 1123-1132.

16. Frisvold SK, Robba C, Guérin C. What respiratory targets should be recommended in patients with brain injury and respiratory failure? Inten Care Med. 2019; 45: 683-686.

17. Mrozek S, Constantin JM, Geeraerts T. Brain-lung crosstalk: Implications for neurocritical care patients. World J Crit Care Med. 2015; 4: 163-178.

18. Schmidt EA, Despas F, Pavy-Le Traon A, Czosnyka Z, Pickard JD, Rahmouni K, et al. Intracranial pressure is a determinant of sympathetic activity. Front Physiol. 2018; 9: 11.

19. Mascia L. Acute lung injury in patients with severe brain injury: A double hit model. Neurocrit Care. 2009; 11: 417-426.

20. Robba C, Ortu A, Bilotta F, Lombardo A, Sekhon MS, Gallo F, et al. Extracorporeal membrane oxygenation for adult respiratory distress syndrome in trauma patients: A case series and systematic literature review. J Trauma Acute Care Surg. 2017; 82: 165-173. 
21. Della Torre V, Badenes R, Corradi F, Racca F, Lavinio A, Matta B, et al. Acute respiratory distress syndrome in traumatic brain injury: How do we manage it? J Thorac Dis. 2017; 9: 5368.

22. Ahmad SB, Menaker J, Kufera J, O'Connor J, Scalea TM, Stein DM. Extracorporeal membrane oxygenation after traumatic injury. J Trauma Acute Care Surg. 2017; 82: 587-591.

23. Muellenbach RM, Kredel M, Kunze E, Kranke P, Kuestermann J, Brack A, et al. Prolonged heparin-free extracorporeal membrane oxygenation in multiple injured acute respiratory distress syndrome patients with traumatic brain injury. J Trauma Acute Care Surg. 2012; 72: 1444-1447.

24. Biscotti M, Gannon WD, Abrams D, Agerstrand C, Claassen J, Brodie D, et al. Extracorporeal membrane oxygenation use in patients with traumatic brain injury. Perfusion. 2015; 30: 407 409.

25. Munoz-Bendix C, Beseoglu K, Kram R. Extracorporeal decarboxylation in patients with severe traumatic brain injury and ARDS enables effective control of intracranial pressure. Crit Care. 2015; 19: 381.

26. Kruit N, Prusak M, Miller M, Barrett N, Richardson C, Vuylsteke A. Assessment of safety and bleeding risk in the use of extracorporeal membrane oxygenation for multitrauma patients: $A$ multicenter review. J Trauma Acute Care Surg. 2019; 86: 967-973.

27. Thomas J, Kostousov V, Teruya J. Bleeding and thrombotic complications in the use of extracorporeal membrane oxygenation. Semin Thromb Hemost. 2018; 44: 20-29.

28. Sy E, Sklar MC, Lequier L, Fan E, Kanji HD. Anticoagulation practices and the prevalence of major bleeding, thromboembolic events, and mortality in venoarterial extracorporeal membrane oxygenation: A systematic review and meta-analysis. J Crit Care. 2017; 39: 87-96.

29. ELSO Anticoagulation Guideline [Internet]; 2014. Available from: https://www.elso.org/Resources/Guidelines.aspx.

30. Kandrotas RJ. Heparin pharmacokinetics and pharmacodynamics. Clin Pharmacokine. 1992; 22: 359-374.

31. Young G. New anticoagulants in children. ASH Education Program Book. 2008; 2008: 245-250.

32. Ranucci M, Ballotta A, Kandil H, Isgrò G, Carlucci C, Baryshnikova E, et al. Bivalirudin-based versus conventional heparin anticoagulation for postcardiotomy extracorporeal membrane oxygenation. Crit Care. 2011; 15: R275.

33. Nagle EL, Dager WE, Duby JJ, Roberts AJ, Kenny LE, Murthy MS, et al. Bivalirudin in pediatric patients maintained on extracorporeal life support. Pediatr Crit Care Med. 2013; 14: e182e188.

34. Maul TM, Massicotte MP, Wearden PD. ECMO biocompatibility: Surface coatings, anticoagulation, and coagulation monitoring. Extracorporeal Membrane Oxygenation: Advances in Therapy. 2016. 27.

35. Chan VH, Monagle $P$, Massicotte $P$, Chan AK. Novel paediatric anticoagulants: A review of the current literature. Blood Coagul Fibrinolysis. 2010; 21: 144-151.

36. Annich GM, Meinhardt JP, Mowery KA, Ashton BA, Merz SI, Hirschl RB, et al. Reduced platelet activation and thrombosis in extracorporeal circuits coated with nitric oxide release polymers. Crit Care Med. 2000; 28: 915-920.

37. Jacobson J. Nitric oxide: Platelet protectant properties during cardiopulmonary bypass/ECMO. J Extra Corpor Technol. 2002; 34: 144-147. 
38. Yen TS, Liau CC, Chen YS, Chao A. Extracorporeal membrane oxygenation resuscitation for traumatic brain injury after decompressive craniotomy. Clin Neurol Neurosurg. 2008; 110: 295-297.

39. Friesenecker B, Peer R, Rieder J, Lirk P, Knotzer H, Hasibeder W, et al. Craniotomy during ECMO in a severely traumatized patient. Acta Neurochir. 2005; 147: 993-996.

40. Zangrillo A, Landoni G, Biondi-Zoccai G, Greco M, Greco T, Frati G, et al. A meta-analysis of complications and mortality of extracorporeal membrane oxygenation. Crit Care Resusc. 2013; 15: 172.

41. Mazzeffi M, Strauss E, Meyer M, Hasan S, Judd M, Abuelkasem E, et al. Coagulation factor levels and underlying thrombin generation patterns in adult extracorporeal membrane oxygenation patients. Anesth Analg. 2019; 129: 659-666.

42. Martucci G, Panarello G, Occhipinti G, Raffa G, Tuzzolino F, Capitanio G, et al. Impact of cannula design on packed red blood cell transfusions: Technical advancement to improve outcomes in extracorporeal membrane oxygenation. J Thorac Dis. 2018; 10: 5813.

43. Martucci G, Panarello G, Occhipinti G, Ferrazza V, Tuzzolino F, Bellavia D, et al. Anticoagulation and transfusions management in veno-venous extracorporeal membrane oxygenation for acute respiratory distress syndrome: Assessment of factors associated with transfusion requirements and mortality. J Inten Care Med. 2019; 34: 630-639.

44. ELSO Guidelines for Adult Respiratory Failure v1.4 [Internet]; 2017 [updated Aug]. Available from: https://www.elso.org/Resources/Guidelines.aspx.

45. Lazzara RR, Magovern JA, Benckart DH, Maher JT, Sakert T, Magovern JG. Extracorporeal membrane oxygenation for adult post cardiotomy cardiogenic shock using a heparin bonded system. ASAIO. 1993; 39: M444-M447.

46. Mahmood S, Bilal H, Zaman M, Tang A. Is a fully heparin-bonded cardiopulmonary bypass circuit superior to a standard cardiopulmonary bypass circuit? Interact Cardiovasc Thorac Surg. 2012; 14: 406-414.

47. Chen $\mathrm{CY}$, Hsu TY, Chen WK, Muo CH, Chen HC, Shih HM. The use of extracorporeal membrane oxygenation in trauma patients: A national case-control study. Medicine. 2018; 97: : e12223.

48. Swol J, Brodie D, Napolitano L, Park PK, Thiagarajan R, Barbaro RP, et al. Indications and outcomes of extracorporeal life support in trauma patients. J Trauma Acute Care Surg. 2018; 84: 831-837.

49. Ried M, Bein T, Philipp A, Müller T, Graf B, Schmid C, et al. Extracorporeal lung support in trauma patients with severe chest injury and acute lung failure: A 10-year institutional experience. Crit Care. 2013; 17: R110.

50. Wu MY, Lin PJ, Tseng YH, Kao KC, Hsiao HL, Huang CC. Venovenous extracorporeal life support for posttraumatic respiratory distress syndrome in adults: The risk of major hemorrhages. Scand J Trauma Resusc Emerg Med. 2014; 22: 56.

51. Zonies D, Merkel M. Advanced extracorporeal therapy in trauma. Curr Opin Crit Care. 2016; 22: 578-583.

52. Lorusso R, Gelsomino S, Parise O, Di Mauro M, Barili F, Geskes G, et al. Neurologic injury in adults supported with veno-venous extracorporeal membrane oxygenation for respiratory failure: Findings from the extracorporeal life support organization database. Crit Care Med. 2017; 45: 1389-1397. 
53. Martucci G, Re VL, Arcadipane A. Neurological injuries and extracorporeal membrane oxygenation: The challenge of the new ECMO era. Neurol Sci. 2016; 37: 1133-1136.

54. Martucci G, Re VL, Marrone G, Caruso S, Arcadipane A. Intracranial hemorrhage during extracorporeal membrane oxygenation: Does family history play a role? Neurol Sci. 2015; 36: 1523-1525.

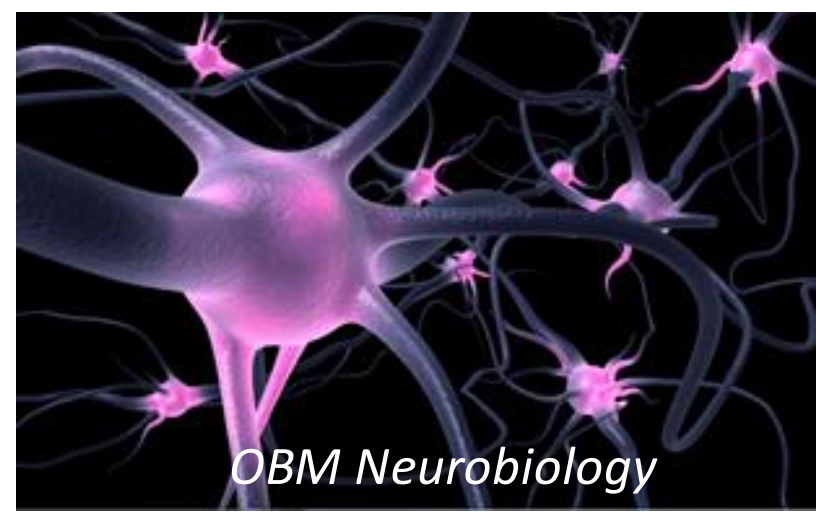

Enjoy OBM Neurobiology by:

1. Submitting a manuscript

2. Joining volunteer reviewer bank

3. Joining Editorial Board

4. Guest editing a special issue

For more details, please visit:

http://www.lidsen.com/journals/neurobiology 